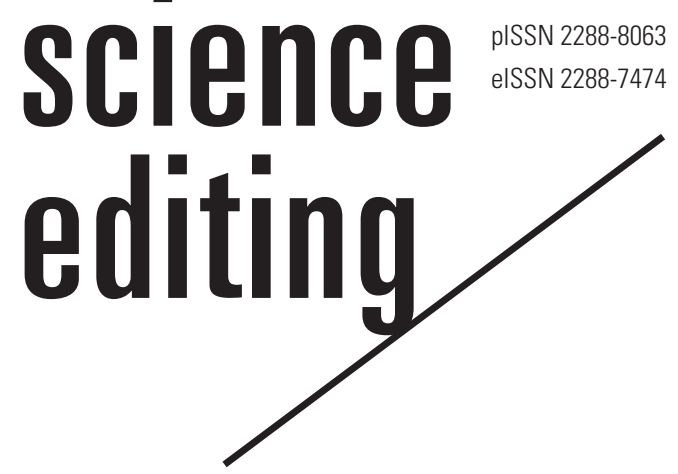

\title{
COVID-19 research trends in the fields of economics and business in the Scopus database in November 2020
}

\author{
Luqman Hakim Handoko \\ Sekolah Tinggi Ekonomi Islam (STEI) SEBI, Depok, Indonesia
}

\section{Abstract}

Purpose: This study explored the state of the literature on coronavirus disease 2019 (COVID-19) in two subject areas: (1) economics, econometrics, and finance, and (2) business, management, and accounting. The study focused on the most productive and influential journals, countries, institutions, documents, and clusters of keywords.

Methods: Data were retrieved from Scopus on November 21, 2020. The search term was the keyword "COVID-19" in the title, abstract, and author's keywords, and the articles were limited to two subject areas. The data were analyzed using VOSviewer and Excel.

Results: In the analysis of 1,719 articles on COVID-19, the most productive journal that published these articles was Gender, Work, and Organization $(\mathrm{n}=49)$. The most productive country and institutions were the United States $(n=526)$ and Universiteit van Pretoria $(n=16)$ and the University of Oxford ( $\mathrm{n}=16)$, respectively. Based on citations, the most influential authors, countries, and journals were Dmitry Ivanov $(\mathrm{n}=233)$, the United States $(\mathrm{n}=1,027)$, and Finance Research Letters $(\mathrm{n}=326)$, respectively. The most cited article was authored by Stefan Gossling $(n=157)$ on the impact of COVID-19 on society, the economy, and tourism. The articles were from 111 countries, of which $85.6 \%$ had collaborations. The keywords of research on COVID-19 formed 14 clusters (e.g., small and medium enterprises, aviation, tourism, banking and finance, supply chain, economic growth, and the digital economy).

Conclusion: The number of COVID-19 articles related to economics and business is fairly large and is continuing to grow significantly. The keyword analysis showed that COVID-19 has had a tremendous impact on all economic sectors.

Received: January 15, 2021

Accepted: January 29, 2021

Correspondence to Luqman Hakim Handoko lukman.hakim.handoko@sebi.ac.id

ORCID

Luqman Hakim Handoko

https://orcid.org/0000-0003-0973-6607
Keywords

Bibliometric analysis; Business and management; COVID-19; Economic impact; Economics and finance 


\section{Introduction}

Background/rationale: The coronavirus disease 2019 (COVID-19) outbreak has become a pandemic, shocking the world. As of December 2, 2020, there were over 63 million confirmed cases and 1.47 million deaths worldwide (https://covid19.who.int). The rapid spread of the virus has forced countries to implement full or partial lockdowns. Various policies such as working from home and social distancing have been implemented. These circumstances placed businesses and the economy under pressure, requiring them to adapt quickly. Correspondingly, the field of research has also experienced rapid changes and adaptation, the most obvious of which is the widespread implementation of policies prioritizing the publication of research related to COVID-19 and providing free access to such research. As result, along with the rapid spread of COVID-19, research on COVID-19 is growing rapidly. Within 1 year, the total number of publications in the Scopus database dealing with COVID-19 exceeded 82,000 (https://www.scopus.com/).

Researchers in the fields of economics and business have certainly not been left behind in responding to this pandemic. With their subject-area expertise, they are examining and analyzing the impacts of COVID-19 on the economy in relation to various topics. Furthermore, given the rapid and vast publication of articles on COVID-19, some studies have been done on the bibliometric analysis based on subject areas in general [1] or specific areas such as sciences and the social sciences [2,3], business and management [4], and environmental studies $[5,6]$. However, bibliometric analyses of COVID-19 by subject area remain limited, especially in economics, business, and finance.

Objectives: This study aimed to fill a small part of this gap by analyzing the economic, business, and finance subject areas and shedding light on the recent state of COVID-19 documents published in these fields. To achieve this goal, this study focused on describing indicators that are relevant for understanding research production and influence, such as authors, journals, institutions, and countries. Furthermore, this study visualized the networks of co-authorship and co-occurrence of keywords and analyzed research streams. These research streams might spark interest among scholars and researchers to explore new directions for future research and discover solutions to current problems.

\section{Methods}

Ethics statement: This study did not involve human subjects; therefore, neither institutional review board approval nor informed consent was needed.
Study design: This study was a descriptive and bibliometric analysis based on a literature database.

Data collection: The data in this study were retrieved on November 21, 2020 from the Scopus database. To obtain the necessary data, this study used the keyword "COVID 19" in the title, abstracts, and author's keywords. The results were restricted to documents listed in the following two subject areas: "economics, econometrics, and finance" and "business, management, and accounting". The strategy used the following search option "TITLE-ABS-KEY (COVID 19) AND (LIMITTO (SUBJAREA, "BUSI") OR LIMIT-TO (SUBJAREA, "ECON")) AND (LIMIT-T (DOCTYPE, "ar" AND (LIMITTO (SRCTYPE, "J"))". In this study, the metadata and refined Scopus result values were retrieved in the CSV dataset format. However, before the bibliometric analysis, the consistency and reliability of the data were checked to address issues such as a lack of consistency in country names and keywords. The data were also standardized to ensure consistency regarding keywords that sometimes appeared in singular or plural, abbreviations, or other forms.

Visualization and statistical methods: The data obtained from the Scopus database were analyzed using VOSviewer software, and simple statistics were calculated using Microsoft Excel.

\section{Results}

Based on a search with the keyword "COVID-19" on November 21,2020 , the results showed approximately 68,793 documents. Nevertheless, since this study was limited to journal articles in two subject areas, 1,979 articles were examined. Interestingly, these two subject areas intersected with 19 other subject areas. Most articles were listed under business, management, and accounting $(\mathrm{n}=1,244,30.9 \%)$, economic, econometrics and finance ( $\mathrm{n}=967,24 \%)$, social sciences $(\mathrm{n}=954$, $23.7 \%$ ), environmental sciences $(n=209,5.2 \%)$, and engineering $(\mathrm{n}=137,3.4 \%)$. The full distribution of COVID-19 articles across the top 10 subject areas is shown in Fig. 1.

According to VOSviewer, the articles were published in 506 different journals. The highest number of articles was published in Gender, Work, and Organization, with 49 publications, followed by Finance Research Letters $(\mathrm{n}=48)$, American Review of Public Administration ( $\mathrm{n}=43)$, Environmental and Resource Economics $(\mathrm{n}=36)$, and the International Journal of Sociology and Social Policy $(\mathrm{n}=34)$. The other most productive journals with the most publications are shown in Table 1.

The records in the Scopus database indicated that authors from 160 institutions and 111 countries published four or more articles. Table 2 shows the most productive institutions and countries related to COVID-19 papers. Universiteit van 


\section{science editing/}

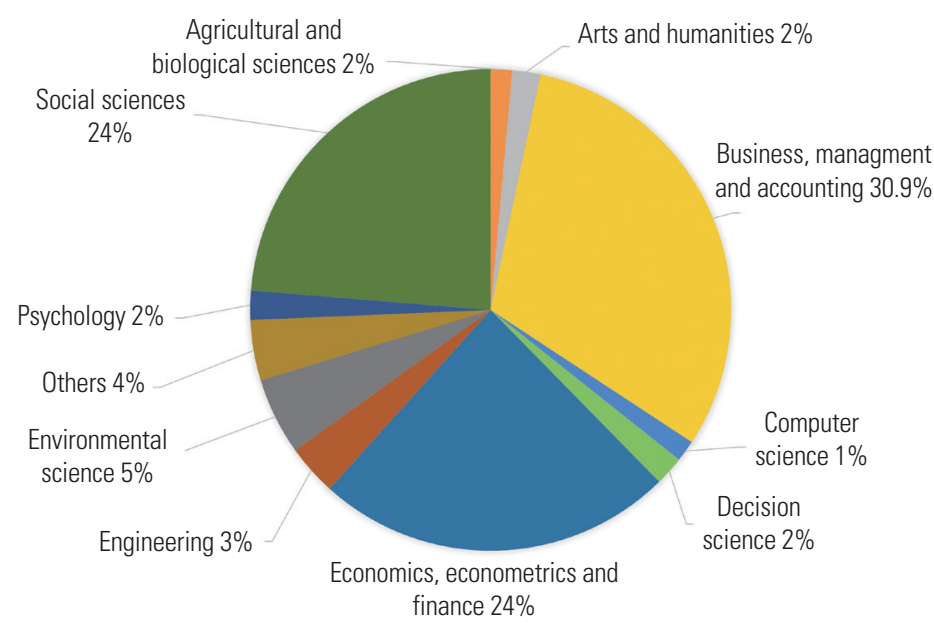

Fig. 1. Distribution of COVID-19 articles based on subject area.

Pretoria $(n=16)$, University of Oxford $(n=16)$, and University of Central Florida $(n=15)$ were the top three institutions publishing COVID-19 research in these fields. The most productive countries were the United States $(n=526)$, United Kingdom $(n=305)$, China $(n=147)$, India $(n=132)$, Australia $(n=130)$, and Germany $(n=102)$, which together published approximately $48.9 \%$ of all publications.

Table 3 lists the most influential authors based on citations recorded by the Scopus database. The most influential author was Ivanov D, with 233 citations, followed by Gossling S $(n=201)$, Hall CM $(n=196)$, Scott $D(n=196)$, and Zhang H $(n=141)$. However, none of these authors were listed among the top five productive authors in terms of publication volume. In the meantime, as shown in Table 3, the top five most influential countries were dominated by the most productive countries in Table 2, such as the United States $(\mathrm{n}=1027)$, United Kingdom $(n=835)$, China $(n=637)$, and Australia $(\mathrm{n}=430)$. However, India, which was the fourth most productive country, was replaced by Canada $(n=460)$ in terms of the number of citations.

Table 3 also presents the influential sources (i.e., journals) based on citations. Finance Research Letters $(\mathrm{n}=326)$ was the most influential journal, followed by Tourism Geographies $(n=235)$, the Journal of Business Research $(n=179)$, the Canadian Journal of Agricultural Economics $(\mathrm{n}=169)$, and the Journal of Sustainable Tourism $(\mathrm{n}=162)$. Finance Research Letters was the only one of these journals that was also among the top five productive journals.

"Pandemics, tourism, and global change: a rapid assessment of COVID-19" published in the Journal of Sustainable Tourism by Gossling et al. [7] was the most frequently cited ( $\mathrm{n}=$ $157)$ article. The second highly cited article $(n=114)$ was entitled, "Predicting the impacts of epidemic outbreaks on global supply chains: A simulation-based analysis on the corona-
Table 1. The most productive journals based on the number of publications

\begin{tabular}{|c|c|}
\hline Source & No. of publications \\
\hline Gender, Work, and Organization & 49 \\
\hline Finance Research Letters & 48 \\
\hline American Review of Public Administration & 43 \\
\hline Environmental and Resource Economics & 36 \\
\hline International Journal of Sociology and Social Policy & 34 \\
\hline Public Administration Review & 32 \\
\hline World Development & 29 \\
\hline $\begin{array}{l}\text { Journal of Public Budgeting, Accounting, and Financial } \\
\text { Management }\end{array}$ & 28 \\
\hline Tourism Geographies & 27 \\
\hline International Journal of Sport Communication & 26 \\
\hline Journal of Air Transport Management & 26 \\
\hline Tijdschrift Voor Economische En Sociale Geografie & 26 \\
\hline IEEE Engineering Management Review & 25 \\
\hline Economic and Political Weekly & 22 \\
\hline Environment, Development, and Sustainability & 22 \\
\hline Journal of Business and Technical Communication & 22 \\
\hline Eurasian Geography and Economics & 21 \\
\hline Indian Journal of Labour Economics & 21 \\
\hline Administrative Theory and Praxis & 20 \\
\hline International Journal of Hospitality Management & 20 \\
\hline Journal of Risk Research & 19 \\
\hline Applied Economic Perspectives and Policy & 18 \\
\hline Canadian Journal of Agricultural Economics & 18 \\
\hline Emerging Markets Finance and Trade & 18 \\
\hline
\end{tabular}

virus outbreak (COVID-19/SARS-CoV-2) case," by Ivanov [8], published in Transportation Research Part E: Logistics and Transportation Review. The other most influential documents are shown in Table 4 [7-16].

Fig. 2 shows collaboration among authors according to their country of affiliation. Large nodes represent the total links of each country. The links between nodes show collaborations between researchers from different countries, and the thickness of the links and distance between the nodes show the frequency of collaboration. Different colors represent 15 different clusters. The country with the most collaboration was the United Kingdom, with 55 links and a total link strength of 299, followed by the United States $(n=64,291)$, Australia $(\mathrm{n}=33,117)$, China $(\mathrm{n}=33,115)$, Germany $(\mathrm{n}=30$, $100)$, France $(n=36,95)$, Canada $(n=31,83)$, Italy $(n=21$, $77)$, New Zealand $(n=25,70)$, and Finland $(n=25,57)$.

Lastly, using VOSviewer software, this study recorded 4,737 
Table 2. The most productive countries and institutions based on the number of publications

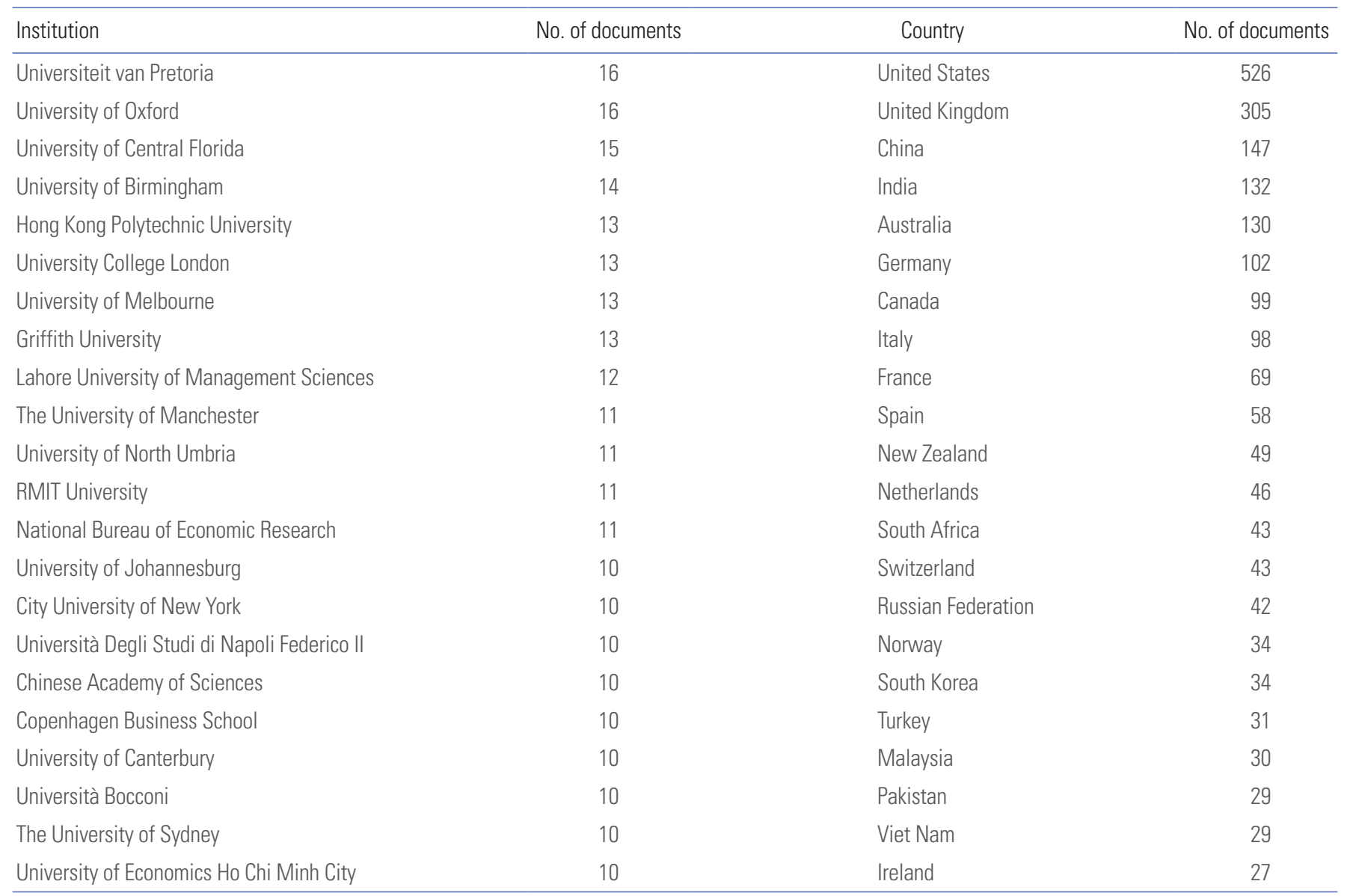

Table 3. The most influential authors, countries, and sources based on citation analysis

\begin{tabular}{|c|c|c|c|c|c|}
\hline Author & Citation & Country & Citation & Source & Citation \\
\hline Gossling S & 201 & United Kingdom & 835 & Tourism Geographies & 235 \\
\hline Scott D & 196 & Canada & 460 & Canadian Journal of Agricultural Economics & 169 \\
\hline Zhang H & 141 & Australia & 430 & Journal of Sustainable Tourism & 162 \\
\hline Wang P & 105 & New Zealand & 333 & Resources, Conservation, and Recycling & 133 \\
\hline Zhu S & 105 & France & 243 & Public Administration Review & 130 \\
\hline Dolgui A & 102 & Sweden & 235 & Journal of Risk Research & 125 \\
\hline Zhang D & 94 & Norway & 217 & Journal of Behavioral and Experimental Finance & 119 \\
\hline Geraghty EM & 78 & India & 120 & International Journal of Health Geographics & 80 \\
\hline Kamel Boulos MN & 78 & Malaysia & 106 & Environment, Development, and Sustainability & 71 \\
\hline Chen $X$ & 68 & Turkey & 106 & International Journal of Production Research & 71 \\
\hline
\end{tabular}


Table 4. The most influential documents based on citations

\begin{tabular}{|c|c|c|}
\hline Document & Topic & Scopus citations \\
\hline Gossling S [7] & The impacts of COVID-19 on tourism & 157 \\
\hline Ivanov D [8] & The impact of COVID-19 on global supply chains & 114 \\
\hline Wang $P[9]$ & The impact of COVID -19 on air pollution reduction & 105 \\
\hline Zhang D [10] & The impact of COVID-19 on financial markets & 78 \\
\hline Kamel Boulos MN [11] & Mapping the spread of COVID-19 in the world & 78 \\
\hline Ivanov D [12] & COVID-19 and supply chain networks & 69 \\
\hline Goodell JW [13] & COVID-19 and financial markets & 55 \\
\hline Al-Awadhi AM [14] & The effect of COVID-19 on stock markets & 49 \\
\hline Sharif $A[15]$ & COVID-19 and oil price volatility shock, the stock market, geopolitical risk, and economic policy uncertainty in the US & 43 \\
\hline Dryhurst S [16] & Public risk perception of COVID-19 & 42 \\
\hline
\end{tabular}

For articles with multiple authors, only the name of the first author is given.

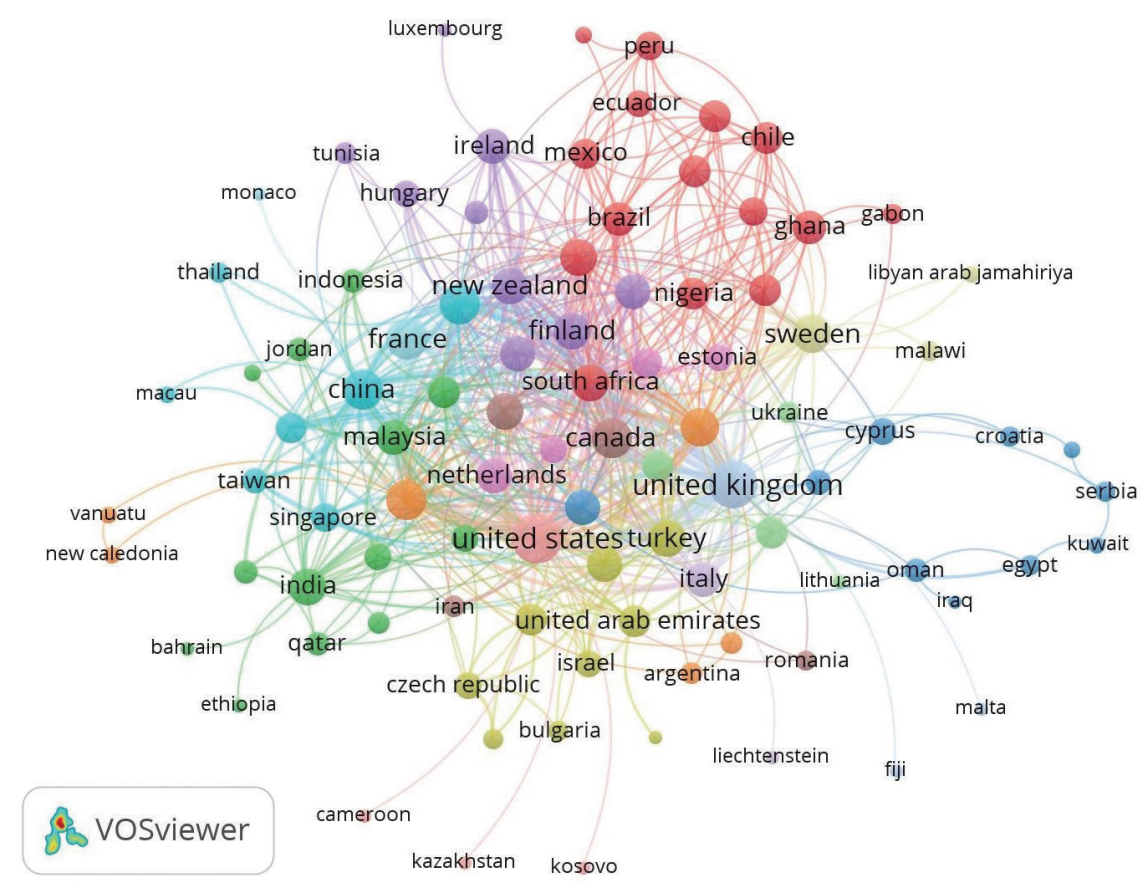

Fig. 2. Visualization of authors' relationships based on countries.

keywords of 1,979 documents. However, only 206 keywords occurred at least five times. Fig. 3 visualizes the co-occurrence of these 206 keywords. The word "COVID-19" was the most common keyword, appearing 1,132 times in the documents, followed by "pandemic" ( $\mathrm{n}=199)$, "coronavirus" $(\mathrm{n}=188)$, "COVID-19 pandemic" $(\mathrm{n}=70)$, "crisis" $(\mathrm{n}=62)$, "China" $(\mathrm{n}=43)$, "lockdown" $(\mathrm{n}=43)$, "resilience" $(\mathrm{n}=38)$, "SARSCoV-2" $(\mathrm{n}=36)$, and "social distancing" $(\mathrm{n}=35)$.

Furthermore, Fig. 3 shows these keywords divided into 14 clusters (each with a different number of keywords), which are represented by colors. The first cluster (red, 26 keywords) focused on the socio-economic impact, digital technology, airline industries, and small to medium enterprises. The second cluster (green, 22 keywords) centered on air quality and pollution, public health, crisis, higher education, food security, and social security. The third cluster (blue, 21 keywords) related to business models, family business, risk management, corporate social responsibility, blockchain, entrepreneurship, and supply chains.

The fourth cluster (yellow, 18 keywords) showed links to 


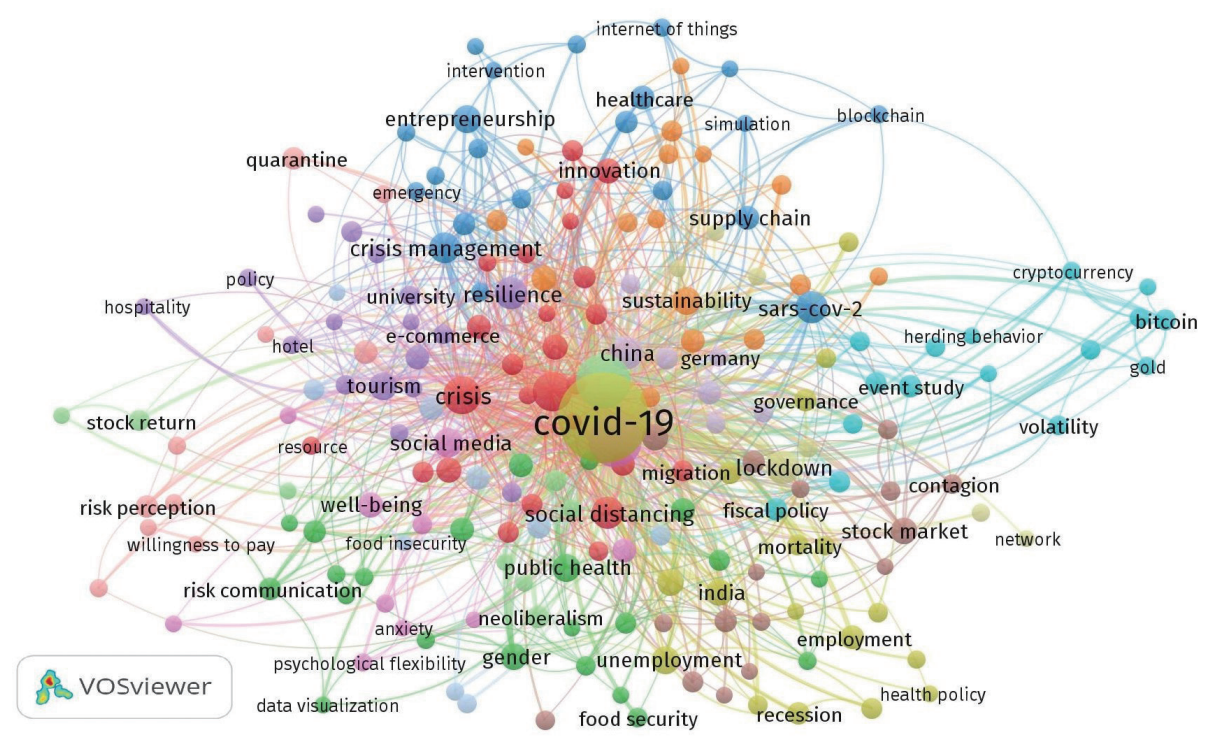

Fig. 3. Visualization of author's keywords co-occurrences network.

micro- and macro-economic themes, with the gross domestic product, economic impact, labor market, employment and unemployment, and work from home. Education, university, online learning, e-commerce, hospitality, hotel, and tourism were the core topics of cluster 5 (purple, 17 keywords). The sixth cluster (light blue, 16 keywords) addressed the impact of COVID-19 on financial crises, with keywords such as financial market, bitcoin and cryptocurrency, fiscal policy, herding behavior, gold, volatility, and liquidity.

The seventh cluster (orange, 16 keywords) showed links to supply chain issues, with topics such as supply chain, disruption, supply chain risk management, supply chain resilience, food supply chain, global supply chain, global value chain, and circular economy. Public policy, informal economy, worklife balance, economic growth, globalization, and investment were the main topics of cluster 8 (brown, 16 keywords). The ninth cluster (lavender, 11 keywords) focused on social media-related issues such as sentiment analysis, well-being, mental health, anxiety, and social media. The 10th cluster (purple, 10 keywords) focused on the impact of COVID-19 on behavior, with keywords such as consumer behavior, the theory of planned behavior, willingness to pay, perceived risk, and risk perception.

The 11th cluster (lime green, nine keywords) focused on emergency management, stock returns, and the public budget. The 12th cluster (light blue, nine keywords) dealt with poverty, food insecurity, disaster, and sustainable development. The 13th cluster (light green, eight keywords) addressed the sports economy, with keywords such as football, sport, and leisure. The 14th cluster (light purple, seven key- words) focused on big data, with keywords including big data and artificial intelligence.

\section{Discussion}

Interpretation: The current study focused on articles published in two subject areas: namely economics, econometrics, and finance; and business, management, and accounting. This study aimed to provide information on the status of publications in these fields related to the impact of COVID-19. As of November 21, 2020, a total of 1979 studies published in these two subject areas were recorded in the Scopus database. The data showed the rapidity of article publications and the responsiveness of the researchers in analyzing the impact of the COVID-19 pandemic on economic sectors around the world.

Based on Tables 2 and 3, the most productive and influential country was the United States followed by the United Kingdom and China. Moreover, Table 4 showed that the top 10 articles addressed the impacts of COVID-19 on risk perception, air pollution, supply chains, the financial market, the tourism industry, and oil prices [7-16]. Furthermore, as shown in the visualization in Fig. 2, the collaboration level between countries is quite high. Of the 111 countries identified, $85.6 \%$ $(n=95)$ had instances of collaboration with other countries. The five countries with the highest total link strength were the United Kingdom, United States, Australia, China, and Germany. However, no instances of collaboration were found for 16 countries, including the Philippines, Brunei Darussalam, Iceland, and Afghanistan.

As shown in Fig. 3, based on the visualization of keyword 
co-occurrence, research on COVID-19 was divided into 14 clusters. This result is in line with the findings of Verma and Gustafsson [4], who identified 18 sub-themes of business management. Furthermore, Fig. 3 presents a variety of studies in every economic sector, including small and medium enterprises, aviation, tourism, banking and finance, the supply chain, economic growth, and the digital economy. Likewise, the number of clusters showed that research has addressed the serious impacts of COVID-19 on the economy from both macro- and micro-economic perspectives.

Limitation: The current study has several limitations. First, this study was focused on two subject areas in the Scopus database, and other databases were excluded from the study. Another limitation was the inclusion of only articles. Consequently, future bibliometric analyses are still needed, including other types of documents and a more comprehensive analysis of COVID-19 studies related to the economy, business, and finance from several databases.

Conclusion: Based on the results of this study and the absence of signs of reductions in COVID-19 cases, it is very possible that COVID-19 research related to the economy and business will continue to grow significantly. By examining and showing the current state of the literature in these two subject areas, this research supplies important information for researchers in the area of economics, business, and finance. This research complements the existing studies on COVID-19, especially related to economics, business, and finance. The results confirm that COVID-19 has seriously affected all economic sectors.

\section{Conflict of Interest}

No potential conflict of interest relevant to this article was reported.

\section{Funding}

The author received no financial support for this article.

\section{Data Availability}

Dataset file is available from: the Harvard Dataverse at: https:// doi.org/10.7910/DVN/LMHPDD

Dataset 1. Raw data of COVID-19 articles from the Scopus database

\section{References}

1. Ruiz-Real JL, Nievas-Soriano BJ, Uribe-Toril J. Has COVID-19 gone viral? An overview of research by subject area.
Health Educ Behav 2020;47:861-9. https://doi.org/10. $1177 / 1090198120958368$

2. Nasir A, Shaukat K, Hameed IA, Luo S, Alam TM, Iqbal F. A bibliometric analysis of corona pandemic in social sciences: a review of influential aspects and conceptual structure. IEEE Access 2020;8:133377-402. https://doi.org/10.1109/ ACCESS.2020.3008733

3. Aristovnik A, Ravselj D, Umek L. A bibliometric analysis of COVID-19 across science and social science research landscape. Sustainability 2020;12:9132. https://doi.org/10.3390/ su12219132

4. Verma S, Gustafsson A. Investigating the emerging COVID-19 research trends in the field of business and management: a bibliometric analysis approach. J Bus Res 2020;118:253-61. https:// doi.org/10.1016/j.jbusres.2020.06.057

5. Casado-Aranda LA, Sanchez-Fernandez J, Viedma-del-Jesus MI. Analysis of the scientific production of the effect of COVID-19 on the environment: a bibliometric study. Environ Res 2021;193:110416. https://doi.org/10.1016/j.envres. 2020.110416

6. Zyoud SH, Zyoud AH. Coronavirus disease-19 in environmental fields: a bibliometric and visualization mapping analysis. Environ Dev Sustain 2020 Oct 6 [Epub]. https:// doi.org/10.1007/s10668-020-01004-5

7. Gossling S, Scott D, Hall CM. Pandemics, tourism, and global change: a rapid assessment of COVID-19. J Sustain Tour 2020;29:1-20. https://doi.org/10.1080/09669582.2020 .1758708

8. Ivanov D. Predicting the impacts of epidemic outbreaks on global supply chains: a simulation-based analysis on the coronavirus outbreak (COVID-19/SARS-CoV-2) case. Transp Res E Logist Transp Rev 2020;136:101922. https:// doi.org/10.1016/j.tre.2020.101922

9. Wang P, Chen K, Zhu S, Wang P, Zhang H. Severe air pollution events not avoided by reduced anthropogenic activities during COVID-19 outbreak. Resour Conserv Recycl 2020;158:104814. https://doi.org/10.1016/j.resconrec.2020. 104814

10. Zhang D, Hu M, Ji Q. Financial markets under the global pandemic of COVID-19. Financ Res Lett 2020;36:101528. https://doi.org/10.1016/j.frl.2020.101528

11. Kamel Boulos MN, Geraghty EM. Geographical tracking and mapping of coronavirus disease COVID-19/severe acute respiratory syndrome coronavirus 2 (SARS-CoV-2) epidemic and associated events around the world: how 21st century GIS technologies are supporting the global fight against outbreaks and epidemics. Int J Health Geogr 2020;19:8. https://doi.org/10.1186/s12942-020-00202-8

12. Ivanov D, Dolgui A. Viability of intertwined supply networks: extending the supply chain resilience angles to- 
wards survivability. A position paper motivated by COVID-19 outbreak. Int J Prod Res 2020;58:2904-15. https:// doi.org/10.1080/00207543.2020.1750727

13. Goodell JW. COVID-19 and finance: agendas for future research. Financ Res Lett 2020;35:101512. https://doi.org/ 10.1016/j.frl.2020.101512

14. Al-Awadhi AM, Alsaifi K, Al-Awadhi A, Alhammadi S. Death and contagious infectious diseases: impact of the COVID-19 virus on stock market returns. J Behav Exp Financ
2020;27:100326. https://doi.org/10.1016/j.jbef.2020.100326

15. Sharif A, Aloui C, Yarovaya L. COVID-19 pandemic, oil prices, stock market, geopolitical risk and policy uncertainty nexus in the US economy: fresh evidence from the waveletbased approach. Int Rev Financ Anal 2020;70:101496. https://doi.org/10.1016/j.irfa.2020.101496

16. Dryhurst S, Schneider CR, Kerr J, et al. Risk perceptions of COVID-19 around the world. J Risk Res 2020;23:9941006. https://doi.org/10.1080/13669877.2020.1758193 